\title{
IMPLEMENTASI METODE BACKGROUND SUBTRACTION DAN MORFOLOGI UNTUK MENDETEKSI OBJEK BERGERAK PADA VIDEO
}

\author{
Dede Saptoadi ${ }^{1}$, Fauziah $^{2}$, Nur Hayati ${ }^{3}$ \\ Fakultas Teknologi Komunikasi dan Informatika, Universitas Nasional ${ }^{1}$ \\ desaptoadi98@gmail.com
}

Submitted October 26, 2020; Revised December 1, 2020; Accepted December 3, 2020

\begin{abstract}
Abstrak
Sistem monitoring menjadi kebutuhan yang meningkat pesat hampir pada seluruh lini publik, seperti jalan raya, taman, gedung, terminal dan masih banyak tempat yang memiliki sistem monitoring. Pendeteksian mengadaptasi pembelajaran objek bergerak dalam pengamatan video untuk memperoleh hasil seperti indra penglihatan manusia. Dengan melakukan pendeteksian objek pada sistem monitoring, maka kita dapat menentukan frame yang menunjukkan posisi objek bergerak. Metode yang dapat digunakan untuk melakukan pendeteksian objek adalah background subtraction dan morfologi, metode tersebut dinilai sesuai diimplementasikan dalam program yang dirancang. Metode penelitian yang dilakukan dibagi menjadi dua tahap, yaitu pengumpulan data yang dilakukan untuk mengumpulkan sample video CCTV dan mencari referensi penelitian terkait. Kemudian tahapan didalam program yang dirancang diantaranya ekstraksi frame, implementasi background subtraction, konversi citra grayscale dan mengubahkan ke dalam bentuk biner, melakukan operasi morfologi opening, membuat masking dan diimplementasikan kedalam video. Dari hasil pengujian program memiliki tingkat keberhasilan 93,3\% dari pengujian dengan pencahayaan terang dan 83,3\% dari pengujian dengan pencahayaan redup.
\end{abstract}

Kata Kunci : Background subtraction, monitoring, morfologi, operasi opening, video

\begin{abstract}
Monitoring systems are a rapidly increasing need in almost all lines of public, such as roads, parks, buildings, terminals and many places that have a monitoring system. Detection adapts learning of moving objects in video observation to obtain results such as the human sense of sight. By detecting objects in the monitoring system, we can determine the frame that shows the position of the moving object. The methods that can be used to de-tect objects are background subtraction and morphology, these methods are considered appro-priate to be implemented in the designed program. The research method used is divided into two stages, namely data collection to collect CCTV video samples and search for related research references. Then the stages that the program goes through include frame extraction, implemen-tation of background subtraction, conversion of grayscale images and converting them into bi-nary form, performing opening morphological operations, making masking and implementing them into video. From the test results the program has a success rate of $93.3 \%$ of the test with bright lighting and $83.3 \%$ of the test with dim lighting.
\end{abstract}

Key Words : Background subtraction, monitoring, morphology, opening operations, video

\section{PENDAHULUAN}

Sistem monitoring merupakan salah satu unsur penting dalam meningkatkan sistem pengawasan pada tempat umum. Pendeteksian mengadaptasi pembelajaran objek bergerak dalam pengamatan video untuk memperoleh hasil seperti indra penglihatan manusia [1].
Sistem monitoring menjadi kebutuhan yang meningkat pesat hampir pada seluruh lini publik, seperti jalan raya, taman, gedung, terminal dan masih banyak tempat yang memiliki sistem monitoring [2]. Meningkatnya kebutuhan akan sistem monitoring dikarenakan fungsinya sebagai sistem pengawasan guna memantau lokasi. 
Dengan melakukan pendeteksian objek pada sistem monitoring, maka kita dapat menentukan frame yang menunjukkan posisi objek bergerak [3].

Untuk melakukan pendeteksian objek dapat diimplementasikan dengan menggunakan metode background subtraction dan morfologi untuk mendeteksi pergerakan objek didalam frame sebuah video.

Penelitian yang dilakukan oleh Khairul Umam dan Benny Sukma Negara untuk mendeteksi pergerakan objek telah menggunakan metode background subtraction dan morfologi menghasilkan tingkat keberhasilan sebesar $80 \%$ [4]. Penelitian yang dilakukan Karina Mariane Kaloh, Vecky C. Poekoel dan Muhamad Dwisnanto Putro menghasilkan akurasi pendeteksian menggunakan metode background subtraction sebesar $80.56 \%$ [5]. Penelitian yang dilakukan Muhammad Affandes dan Afdi Ramadani untuk mendeteksi gerak banyak objek dengan metode background subtraction menghasilkan akurasi 88.3\% [6].

Berdasarkan penelitian terdahulu, implementasi background subtraction dinilai berguna untuk mendeteksi pergerakan objek dalam sistem monitoring sebab menghasilkan akurasi yang dinilai besar.

\section{METODE PENELITIAN}

\section{Kebutuhan Perancangan Sistem}

Program yang dirancang membutuhkan beberapa peralatan pendukung yang terdiri dari hardware dan software.

1) Kebutuhan hardware Laptop Intel® CoreTM i5-7200U $2.5 \mathrm{GHz} 64$ bit dengan RAM 12GB, digunakan untuk membangun program. CCTV Resolution 1080p, Lens: f2.5mm DFOV 112 degree, digunakan sebagai media rekam untuk sample video yang diujikan.

2) Kebutuhan software

Draw.io, digunakan untuk mendesain flow dari penelitian yang dilakukan, MATLAB R2017b, software yang digunakan untuk membangun program, YI Home Camera, aplikasi mobile berbasis Android yang digunakan untuk mengumpulkan video hasil rekam dari CCTV, Microsoft Excel digunakan untuk menghitung hasil pengujian.

\section{Background subtraction dan Operasi Morfologi Diimplementasikan}

Background subtraction merupakan metode yang dapat difungsikan untuk mendeteksi perbedaan dari frame video dengan frame referensi [7], dengan tujuan untuk memisahkan antara objek (yang bergerak) dengan background sehingga terdeteksi obyek tersebut [8]. Pada penelitian ini digunakan tahapan implementasi metode background subtraction sebagai berikut: 


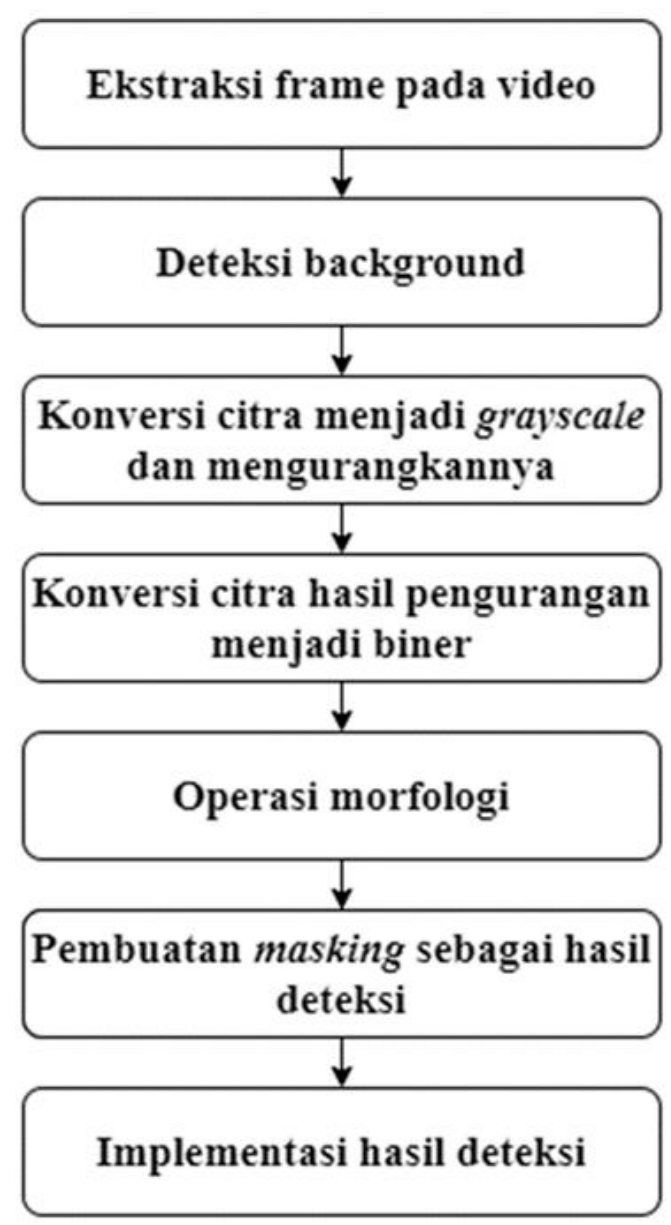

Gambar 1. Tahapan program

Tahapan diatas menjelaskan alur dari program serta implementasi background subtraction dan operasi morfologi, tahapannya yaitu:

1) Ekstraksi frame video

Untuk melakukan ekstraksi frame video, digunakan rumus:

Total Frame $=$ Length $\times$ Frame Rate

Dengan keterangan, sebagai berikut:

Total Frame, jumlah frame dalam satu video yang diekstrasi

Length, panjang durasi video dalam satuan detik (second)

Frame Rate, frame rata-rata perdetik dalam satu video

2) Mencari frame background secara otomatis

Untuk mencari background frame secara otomatis dicari dengan menghitung nilai modus pada setiap frame [9], dengan rumus:

$$
\begin{aligned}
& R^{\prime}=\frac{R}{R+G+B} \\
& G^{\prime}=\frac{G}{R+G+B} \\
& B^{\prime}=\frac{B}{R+G+B}
\end{aligned}
$$

Dari rumus diatas, maka didapat background dari frame tersebut.

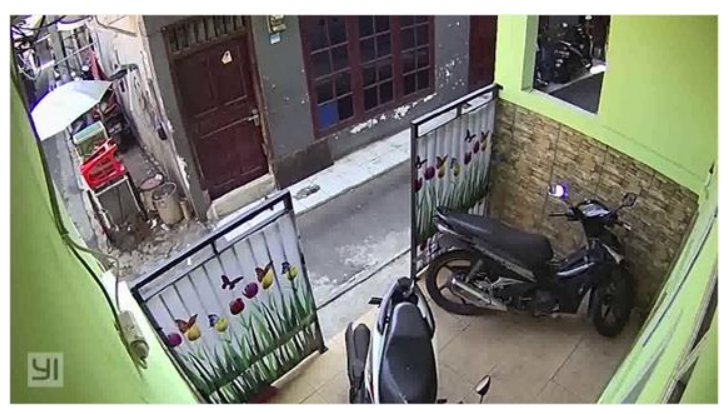

Gambar 2. Sample Hasil Pencarian Background dengan Menghitung Nilai Modus pada Setiap Frame

3) Konversi grayscale pada foreground dan background

Citra RGB yang telah didapat dari setiap frame kemudian dikonversikan menjadi grayscale [10].

\section{Tabel 1. Hasil Konversi Frame RGB} Menjadi Grayscale

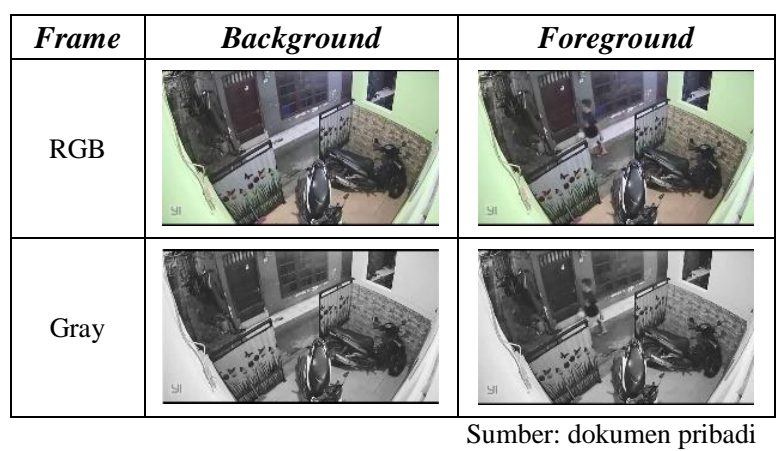

Kemudian dilakukan pengurangan pada citra grayscale dari foreground dan background maka akan didapat hasil seperti gambar dibawah ini. 


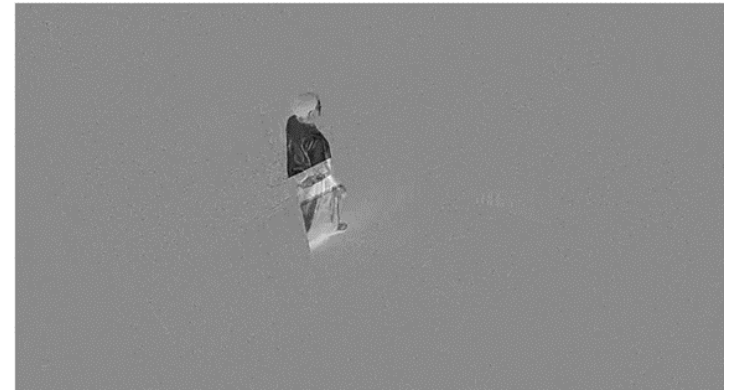

Gambar 3. Hasil Pengurangan Foreground dengan Background

4) Konversi menjadi biner Untuk melakukan perubahan dari citra grayscale menjadi citra biner, dilakukan dengan rumus prosesnya yaitu:

$g(x, y)=\left\{\begin{array}{l}1 \text { if } f(x, y) \geq T \\ 0 \text { if } f(x, y)<T\end{array}\right.$

Dengan keterangan:

$\mathrm{g}(\mathrm{x}, \mathrm{y})$ : Nilai citra biner

$\mathrm{f}(\mathrm{x}, \mathrm{y})$ : Citra grayscale

$\mathrm{T}$ : Nilai ambang

Dengan menggunakan pendekatan metode otsu yaitu menentukan variabel yang dapat memberikan perbedaan antara dua atau lebih variasi yang ada. Hal ini akan memaksimalkan variabel untuk membagi objek menjadi latar depan (foreground) dan latar belakang (background) [11].

Maka akan didapat citra biner seperti gambar dibawah ini.

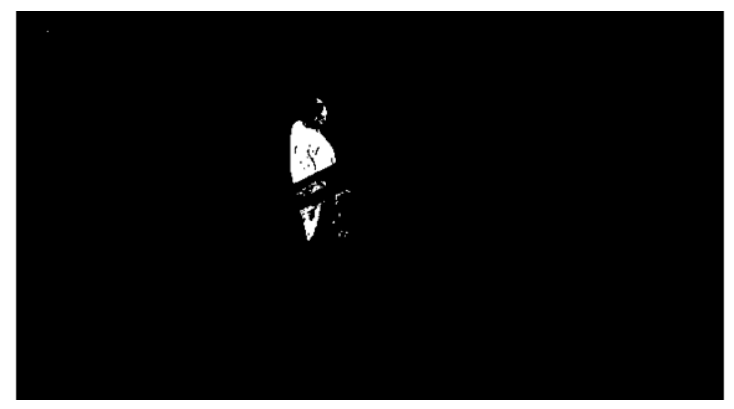

Gambar 4. Hasil Konversi dari Grayscale menjadi Citra Biner
5) Melakukan operasi morfologi opening

Operasi morfologi pada citra merupakan proses berupa pendekatan topologi dan berbentuk geometri untuk kemudian dilakukan analisis pada citra [12]. Operasi morfologi terdiri dari 4 jenis, diantaranya dilasi, erosi, opening dan closing. Pada penelitian ini, digunakan operasi opening untuk menghilangkan noise dari citra yang digunakan. Operasi opening akan menghilangkan piksel yang terang secara menyeluruh dengan rumus:

$A \circ B=(A \ominus B) \oplus B$

Dimana,

A : Nilai citra asli

B : Matriks operator atau disebut structuring element

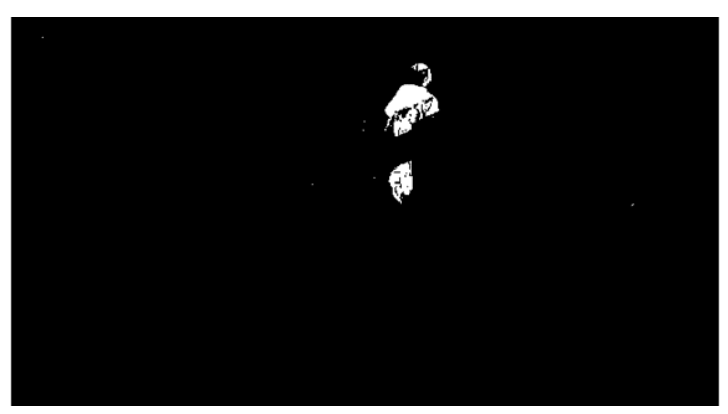

Gambar 5. Citra Asli, Citra Hasil Konversi menjadi Biner

Dicontohkan dilakukan operasi morfologi opening pada Gambar 5, maka didapatkan citra hasil operasi seperti pada Gambar 6 .

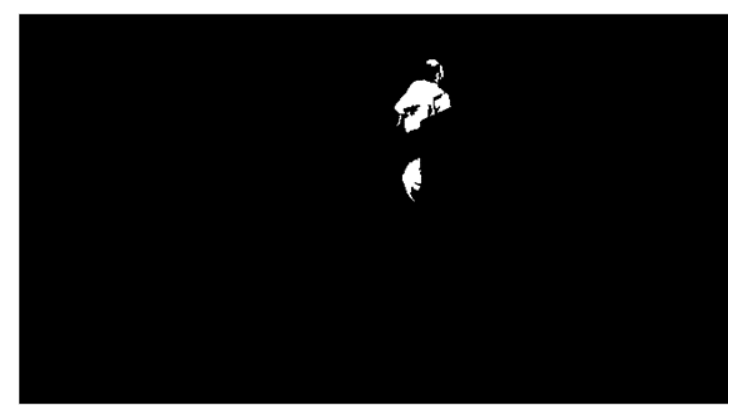

Gambar 6. Citra Hasil Operasi Morfologi Opening 
6) Pembuatan masking untuk mendeteksi objek

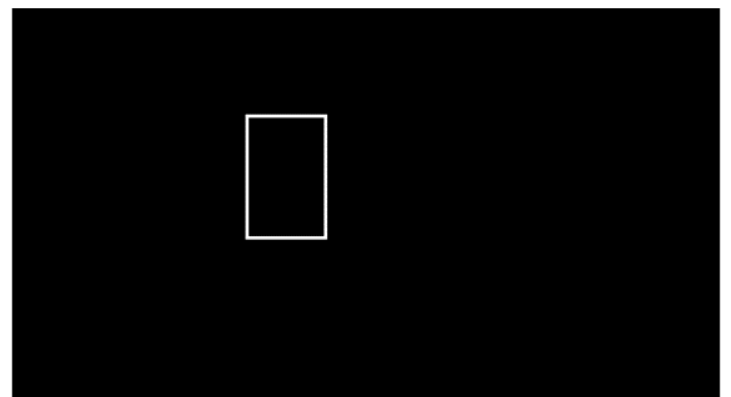

Gambar 7. Pembuatan masking

Masking digunakan untuk mendeteksi objek bergerak yang berhasil dideteksi, yang kemudian akan diterapkan sebagai penanda pergerakan objek [13].

7) Hasil deteksi dijalankan secara sekuensial (berupa video)

Dari hasil deteksi yang telah dilakukan, maka frame akan dijalankan menjadi video kembali.

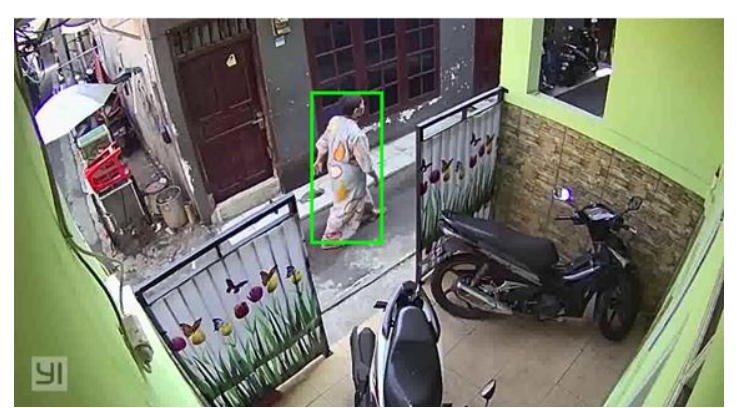

Gambar 8. Implementasi hasil deteksi dalam video

Dari Gambar 8 dapat dilihat masking yaitu kotak berwarna hijau sebagai penanda objek bergerak dalam frame.

\section{HASIL DAN PEMBAHASAN}

\section{Pengujian}

Pengujian dilakukan dengan dua kondisi pencahayaan, yaitu pada siang hari saat kondisi matahari bercahaya terang dan pada saat malam hari saat pencahayaan redup hanya mengandalkan lampu.

\begin{tabular}{|c|c|c|c|c|}
\hline Sample52 & Terang & Tidak Ada & Tidak Terdeteksi & $100 \%$ \\
\hline Sample53 & Terang & Ada & Terdeteksi & $100 \%$ \\
\hline Sample54 & Terang & Ada & Terdeteksi & $100 \%$ \\
\hline Sample55 & Terang & Ada & Terdeteksi & $100 \%$ \\
\hline Sample56 & Terang & Ada & Tidak Terdeteksi & $0 \%$ \\
\hline Sample57 & Terang & Ada & Terdeteksi & $100 \%$ \\
\hline Sample58 & Terang & Ada & Terdeteksi & $100 \%$ \\
\hline Sample59 & Terang & Ada & Terdeteksi & $100 \%$ \\
\hline Sample60 & Terang & Ada & Terdeteksi & $100 \%$ \\
\hline Sample61 & Redup & Ada & Terdeteksi & $100 \%$ \\
\hline Sample62 & Redup & Tidak Ada & Tidak Terdeteksi & $100 \%$ \\
\hline Sample63 & Redup & Ada & Terdeteksi & $100 \%$ \\
\hline Sample64 & Redup & Tidak Ada & Tidak Terdeteksi & $100 \%$ \\
\hline Sample65 & Redup & Tidak Ada & Tidak Terdeteksi & $100 \%$ \\
\hline Sample66 & Redup & Ada & Terdeteksi & $100 \%$ \\
\hline Sample67 & Redup & Ada & Terdeteksi & $100 \%$ \\
\hline Sample68 & Redup & Ada & Terdeteksi & $100 \%$ \\
\hline Sample69 & Redup & Ada & Tidak Terdeteksi & $0 \%$ \\
\hline Sample70 & Redup & Ada & Terdeteksi & $100 \%$ \\
\hline Sample71 & Redup & Ada & Terdeteksi & $100 \%$ \\
\hline
\end{tabular}

Gambar 9. Data pengujian

Gambar 9 menampilkan beberapa data pengujian yang totalnya sebanyak 120 data uji dengan pembagian 60 data dengan kondisi pencahayaan terang dan 60 data dengan kondisi pencahayaan redup.

Nilai dari hasil pengujian dinyatakan dengan keterangan $100 \%$ untuk data video yang sukses terdeteksi pergerakan objeknya dan $0 \%$ untuk data video dengan pergerakan objek yang tidak terdeteksi [14]. Persentase keberhasilan dihitung dengan rumus:

$$
\text { Keberhasilan }(\%)=\frac{D B}{T D P} \times 100
$$

Dengan keterangan

DB : Data dengan hasil 100\%

TDP: Total data pada masing-masing kondisi pencahayaan 


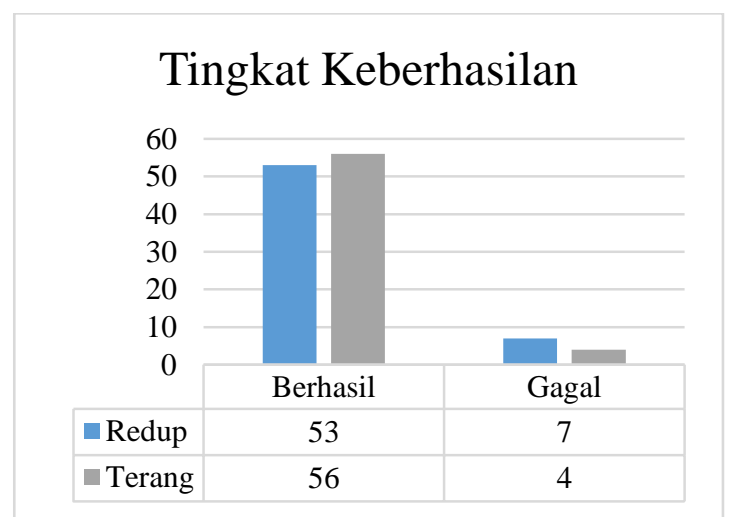

\section{Gambar 10. Tingkat Keberhasilan Pengujian Data}

Dari Gambar 10 dijelaskan bahwa tingkat keberhasilan selama pengujian dibagi menjadi 2 kondisi yang didasarkan pada faktor pencahayaan, diantaranya pencahayaan redup dan terang.

Kondisi redup menghasilkan persentase keberhasilan sebesar 88,3\% dari total 60 data dengan kondisi redup pencahayaan, faktor kegagalan pendeteksian selain karena faktor cahaya juga dari objek yang kurang jelas terbaca pada kamera. Kemudian untuk kondisi dengan pencahayaan terang tingkat keberhasilan sebesar 93,3\% dari total 60 data, persentase keberhasilan pada kondisi ini lebih tinggi karena faktor terpenting yaitu pencahayaan yang sudah cukup jelas, tingkat kegagalan terdeteksi dikarenakan objek terlalu kecil dan berada disudut kamera.

\section{SIMPULAN}

Berdasarkan penelitian diatas, maka kesimpulan yang didapat, yaitu program yang dirancang memiliki tingkat keberhasilan 93,3\% dari pengujian dengan pencahayaan terang dan $83,3 \%$ dari pengujian dengan pencahayaan redup. Berdasarkan tingkat keberhasilan, persentase pencahayaan yang redup lebih kecil dikarenakan faktor pergerakan objek yang minim dalam pencahayaan yang redup dan untuk persentase pen- cahayaan terang memiliki tingkat konsentrasi pendeteksian yang lebih baik.

\section{DAFTAR PUSTAKA}

[1] E. A. Pambudi, A. Y. Badarudin, and D. K. Hakim, "Analysis Thresholding Sauvola pada Background Subtraction untuk Deteksi Objek Bergerak," J. Inform., vol. 6, no. 2, pp. 300-304, 2019, doi: 10.31311/ji.v6i2.6164.

[2] N. N. Putri, "Aplikasi Pendeteksi Objek bergerak pada Image Sequence Dengan Metode Backround Substraction," J. Teknol. Rekayasa Vol., vol. 21, no. 3, pp. 162-172, 2016.

[3] R. Muhamad, T. Yulianti, S. R. Sulistiyanti, S. Purwiyanti, and F. X. A. Setyawan, "Deteksi Objek Bergerak Pada Video Bawah Air Menggunakan Metode Frame Differencing," J. EECCIS, vol. 13, no. 2, pp. 100-104, 2019.

[4] K. Umam and B. S. Negara, "Deteksi Obyek Manusia Pada Basis Data Video Menggunakan Metode Background Subtraction Dan Operasi Morfologi," J. Core IT (Jurnal Has. Penelit. Ilmu Komput. dan Teknol. Informasi), vol. 2, pp. 31-40, 2016.

[5] K. M. Kaloh, V. C. Poekoel, and M. D. Putro, "Perbandingan Algoritma Background Subtraction dan Optical Flow Untuk Deteksi Manusia," $J$. Tek. Inform., vol. 13, no. 1, pp. 1-9, 2018 , doi: 10.35793/jti.13.1.2018.20186.

[6] M. Affandes and A. Ramadani, "Menggunakan Background Substraction Dan Deteksi Tepi Sobel," Semin. Nas. Teknol. dan Rekayasa, no. 255, pp. 1-6, 2017.

[7] A. Miranto, S. R. Sulistiyanti, and F. X. Arinto Setyawan, "Adaptive Background Subtraction for Monitoring System," 2019 Int. Conf. Inf. Commun. Technol., pp. 153-156, 
2019

doi: 10.1109/ICOIACT46704.2019.89385 01.

[8] N. Wahyudi, V. Suhartono, and R. A. Pramunendar, "Background Subtraction Berbasis Self Organizing Map Untuk Deteksi Objek Bergerak," Syst. Inf. Syst. Informatics J., vol. 1, no. 1, pp. 42-51, 2015, doi: 10.29080/systemic.v1i1.283.

[9] A. Solichin and A. Harjoko, "Metode Background Subtraction untuk Deteksi Obyek Pejalan Kaki pada Lingkungan Statis," Semin. Nas. Teknol. Inf. 2013, pp. 1-6, 2013.

[10] J. M. Mchugh, J. Konrad, V. Saligrama, and S. Member, "Foreground-Adaptive Background Subtraction," IEEE Signal Process. Lett., vol. 16, no. 5, pp. 390-393, 2009.

[11] S. Bhahri and Rahmat, "Transformasi Citra Biner Menggunakan Metode
Thresholding dan Otsu Thresholding," J. Sist. Inf. dan Teknol. Inf., vol. 7, no. 2, pp. 195203, 2018.

[12] A. Susanto, "Matematika Citra Digital Untuk Ekstraksi Area Plat Nomor," J. Pseudocode, vol. VI, no. 1, pp. 49-57, 2019.

[13] C. Prabowo and Zurnawita, "Penerapan Metode Background Subtraction Dengan Menggunakan Kandidat Sampling Background Applied Background Subtraction Method Used Background," J. Teknol. Inf. dan Ilmu Komput., vol. 5, no. 6, pp. 731-736, 2018, doi: 10.25126/jtiik201856115.

[14] S. I. Syafi'i, R. T. Wahyuningrum, and A. Muntasa, "Segmentasi Obyek Pada Citra Digital Menggunakan Metode Otsu Thresholding," $J$. Inform., vol. 13, no. 1, pp. 1-8, 2016, doi: 10.9744/informatika.13.1.1-8. 